\title{
Age as a Variable in Insurance Pricing and Risk Classification
}

\author{
Mary Kelly and Norma Nielson \\ Haskayne School of Business, University of Calgary, Calgary, AB T2N 1N4, Canada. \\ E-mail: norma.nielson@haskayne.ucalgary.ca
}

This paper examines the use of age in the delivery of personal insurance to Canadians. We find that age is a reliable classification variable and one that can be practically implemented. Primary concerns about age as a classification variable centre around the issue of social acceptability. In particular, we focus on age and auto insurance where, unlike life and health insurance, there exists no strong intuitive causal relationship. In North America, the frequency and severity of auto accidents are highly correlated with age, in a nonlinear relationship. The data produce a distinctive U-shape curve when accident history is graphed against age. However, heterogeneity in driving abilities for both younger and older ages emphasizes that this relationship is one of correlation. To assess whether there exists a "better" classification variable, this paper explores possible alternatives to age. In the end, none of the variables examined captures a driver's risk with the same degree of accuracy as can be achieved using age.

The Geneva Papers (2006) 31, 212-232. doi:10.1057/palgrave.gpp.2510082

Keywords: risk classification; age; automobile insurance; underwriting

\section{Introduction}

As the Ontario Human Rights Commission notes, "society has accepted age-based criteria as a way to structure policies and programmes". ${ }^{1}$ Recently, however, the Law Commission of Canada raised the following questions:

Is it appropriate to use age in our legislation, public policies and programmes? Are age-based distinctions in Canadian law just? ... Could other concepts better reflect the diversity of life choices among Canadians? ${ }^{2}$

Spurred by the challenge implicit in these statements, we examine here the relationship between age and personal insurance with an emphasis on driving ability and the pricing of automobile insurance.

In the first section, we review the relationship between age and driving ability, including information about both young and elderly drivers. For young drivers, the

\footnotetext{
* The authors gratefully acknowledge the generosity of Michael Miller in allowing us to include his work in this article. We are also thankful for the funding and support provided for this research by the Law Commission of Canada. We also thank the editors and the referees for their helpful comments.

${ }^{1}$ Ontario Human Rights Commission (2002).

${ }^{2}$ Law Commission of Canada (2004, p. 3).
} 
risk-taking behaviours of teens, the length of time it takes to learn to drive a car proficiently, and the effects of such facts on the accident histories are discussed. For elderly drivers, we examine the relationship between ageing and the sensory and cognitive skills required to drive a car. This evidence demonstrates functional limitations and environmental factors that are strongly correlated with age and that make both the young and elderly higher risk drivers.

The next section explores the actuarial issues which make age a central issue in the delivery of private insurance. We define criteria for efficient underwriting variables and examine the results and effectiveness of using age as a classification variable for life, health and auto insurance, both in theory and in practice. We conjecture that both the high cost of insurance for those who can least afford it and the lack of a clear intuitive and causal relationship between driving ability and age are the prime reasons that age is a contentious classification variable for auto insurance while the same is not true for other lines of personal insurance.

The penultimate section examines a set of variables that have been identified as having potential to permit the insurance industry to rely less heavily on age as a classification variable. Specifically, we consider the number of years licensed, driving record, discounts offered to youth, and an insurance score that incorporates elements of one's credit history.

The last section presents our conclusions and discusses some implications of that result.

\section{Functional abilities and age}

The gerontology literature often describes age in terms of either chronological or functional status. Chronological age is simply the number of years since birth. Functional age is an indexing tool that equates human ability in terms of common performance standards. Because the latter can only be determined after a comprehensive examination, it is not useful for categorizing a large population quickly. The relationship between functional age and chronological age is the result of a dynamic process. Discrepancies between an individual's chronological and functional age create challenges for those charged with the development of robust and responsive public policies. While we conjecture that functional age would be a fairer measurement of ability and risk exposure, it is chronological age that is traditionally used in insurance. For that reason age in this article refers to chronological age unless otherwise noted.

In Canada, both the frequency and severity of auto accidents are highly correlated with age. Nominally young drivers have the greatest frequency of accidents, but when adjusted for distance travelled, seniors have the worst accident history. Similarly, young drivers have the highest fatality rate. Figure 1 relates the proportion of driver fatalities by age to the number of drivers by age in Canada for 1999-2003. Overall, the U-shaped curve associated with accident history by age consistently reveals the disproportionate number of young and old drivers killed in traffic accidents.

The remainder of this section reviews the sociological and functional aspects of ageing with particular attention to the interplay between age and the abilities needed 


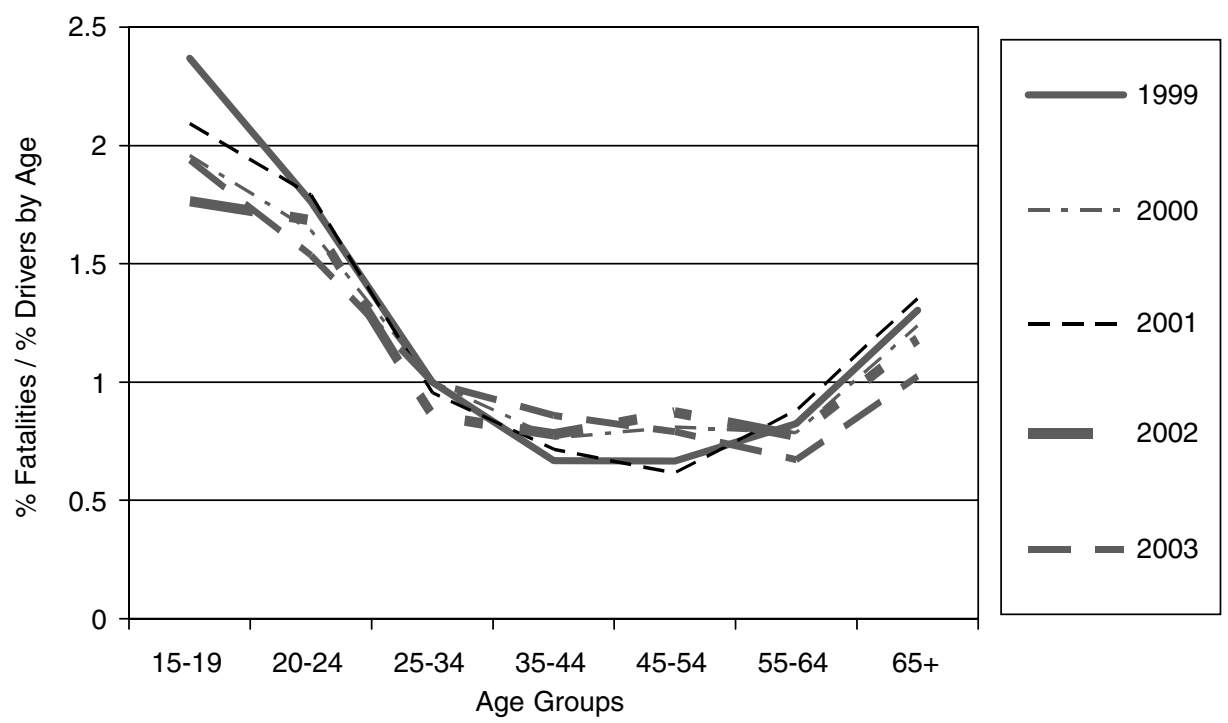

Figure 1. Proportion of driver fatalities by age to driver population by age. Source: Author Tabulation.

to operate a motor vehicle. An important fact that is often not explicit in the literature (or in graphs such as Figure 1) is the heterogeneity among the youngest and the oldest drivers. Insurers observe more variability in the accident histories of drivers in these two age groups than any others.

\section{The younger driver}

Young people take more risks than the rest of the driving population and drive in more risky situations. Compounding this is the young driver's lack of driving experience. ${ }^{3}$ All of this leads to an accident rate that exceeds that of the general driving population. Nicoletta ${ }^{4}$ reports that in the year 2000, persons aged 16-24 years accounted for 15 per cent of Canada's population, 13 per cent of total driving licenses, and only 7 per cent of the total kilometers driven. Younger drivers drove greater distances on weekends and more often after midnight than older drivers and were more likely to be involved in collisions than any other age group. In all, 50 per cent more younger drivers were involved in collisions than older drivers despite the fact that those aged 55 years and over drove more than three times the distance. ${ }^{5}$ The Public Health Agency of Canada reports that traffic accidents are the leading cause of death for 15-19 years old.

\footnotetext{
${ }^{3}$ McKnight and McKnight (2003).

${ }^{4}$ Nicoletta (2002).

${ }^{5}$ Ibid.
} 
Table 1 Per centage of fatal crashes by characteristic, 2002

\begin{tabular}{lccc}
\hline Driver age (years) & 16 & $17-19$ & $20-49$ \\
\hline Driver error (\%) & 85 & 78 & 66 \\
Speeding (\%) & 37 & 34 & 24 \\
Single vehicle (\%) & 50 & 46 & 40 \\
3+ occupants (\%) & 27 & 24 & 18 \\
Drivers killed with 0.10+ BAC (\%) & 11 & 22 & 43 \\
\hline
\end{tabular}

Source: Beginning Teenage Drivers. Insurance Institute for Highway Safety. September 2003.

\section{Driving maturity}

All novice drivers face greater risks than experienced drivers. Renge ${ }^{6}$ found that experienced drivers could understand better the signals used in traffic situations than could novice drivers. New drivers have difficulty in adequately searching the roadway before making a maneuver such as a lane-change, ${ }^{7}$ are unable to adjust speed and driving distance to driving conditions, cannot compensate for a restricted field of view, and are easily distracted. ${ }^{8}$ As noted by Shinar et al. ${ }^{9}$ even seemingly physical tasks, such as shifting gears, are more difficult for newer drivers because of the newness of the task. Not surprisingly, driver inexperience is cited as a contributing factor in fatal crashes at a much higher rate (3.41 per cent) for young drivers than for middle-aged drivers $\left(0.62\right.$ per cent) ${ }^{10}$

\section{Risk-taking behaviours}

Voluntary risk-taking behaviours - the cause of a majority of at-fault accidents by young drivers ${ }^{11}$ - include the use of drugs and alcohol, driving too fast, and driving in unsafe situations. Evidence of risk-taking behaviour in the United States is illustrated in Table 1, which presents data on the most common cause of crashes for young American drivers. These outcomes are mirrored in the Canadian experience ${ }^{12}$ and are, in fact, a predictable result of young Canadian drivers partaking in more high risk driving behaviours than other drivers - 38 per cent admit to engaging in risky driving behaviours and nearly all ( 93 per cent) speed. Even more telling is that over 20 per cent of those 16-19 years old and 26 per cent of those 20-24 years old reported having received a moving traffic violation in the past 12 months compared to 9 per cent of those 35-44 years old. ${ }^{13}$

\footnotetext{
${ }^{6}$ Renge (2000).

${ }^{7}$ Underwood et al. (2002).

${ }^{8}$ Clarke et al. (2005).

${ }^{9}$ Shinar et al. (1998).

${ }^{10}$ Zhang et al. (1998).

${ }^{11}$ Clarke et al. (2005).

12 See, for example Zhang et al. (1998).

${ }^{13}$ Beirness et al. (2004a).
} 
216

The Statistical Report on the Health of Canadians ${ }^{14}$ indicates that approximately one-fourth of young Canadians use at least one illicit drug. Zhang et al. ${ }^{15}$ find the rate of illicit drug usage among fatal crashes in Canada between 1984 and 1993 among under-25 drivers is double that observed for drivers 25-64 years old. In contrast, Beirness et al. ${ }^{16}$ find that teenage drivers are much less likely to have driven after drinking than any other age group and teen drivers account for only 5 per cent of all impaired driving trips. But Zhang et al. ${ }^{17}$ found that low levels (below the legal impairment level of $80 \mathrm{mg} / \mathrm{l}$ ) of alcohol impairment were twice as common in fatal crashes involving young drivers than middle-aged drivers.

Driving too fast is the most common moving violation of young drivers in the U.K. and the importance of speeding as a contributory factor in injury-producing accidents declines with age. ${ }^{18}$ Zhang et al. ${ }^{19}$ find excessive speed to be a factor in 18 per cent of fatal crashes among young Canadian drivers, but represents less than 10 per cent of fatal crashes among middle-aged drivers. That study also finds fatal crashes involving young at-fault Canadian drivers are most likely to occur between midnight and four in the morning. Driver usage of seatbelts at the time of a fatal crash was significantly (50 per cent) lower for young drivers than for middle-aged drivers.

\section{The older driver}

Like many other nations Canada faces an ageing population. In 2004, the elderly ${ }^{20}$ comprised approximately 13.1 per cent of the population - a total of 4.1 million Canadians. Statistics Canada projects that almost 8 million people (23.1 per cent of the population) will be of the age of 65 years and over in 2016. The changing composition of the population is reflected in a changing population of drivers. By the year 2025, the proportion of drivers who are elderly or disabled will be approaching 20 per cent. ${ }^{21}$

Senior men are far more likely to drive than senior women. In 55 per cent of senior households where the husband held a valid license, the man was the exclusive driver of the family car, whether or not the wife was licensed. In general, senior women drive shorter distances than senior men. Bess ${ }^{22}$ found 38 per cent of women and 35 per cent of men drive $15 \mathrm{~km}$ or less per day.

Impairments of sensory, cognitive, and other functions are known to increase with age. Because age-related declines tend to be highly correlated, it can be difficult to attribute poor driving to any specific age-related disability. ${ }^{23}$ Despite this challenge,

${ }^{14}$ Health Canada (1999).

${ }^{15}$ Zhang et al. (1998).

${ }^{16}$ Beirness et al. (2004b).

${ }^{17}$ Zhang et al. (1998).

${ }^{18}$ Clarke et al. (2005).

19 Zhang et al. (1998).

${ }^{20}$ Defining 'old' or 'senior' is a contentious issue throughout the literature. For our purposes, since most demographic data and insurance risk classification variables use the age 65 years as the threshold for 'old', we follow this convention and use the terms 'elderly', 'old' and 'senior' interchangeably.

${ }^{21}$ Mitchell (1997).

22 Bess (1999).

${ }^{23}$ McKnight and McKnight (1999). 
the subsections below review the relevant literature on several discrete functional abilities that tend to decline with age and that are known to affect driving ability.

\section{Sensory skills}

The two most important sensory abilities that affect driving are hearing and vision. Hearing loss makes drivers less able to hear important cues while driving. But visual impairment that becomes significantly more prevalent with increasing age is perhaps the most extensively studied characteristic in older drivers.

Two aspects of vision are particularly important with respect to elderly drivers: visual acuity and visual field. Visual acuity, which declines with age, ${ }^{24}$ refers to the ability to perceive spatial detail at a given distance. Reduced visual acuity means it takes longer to distinguish the information being presented visually with respect to road conditions and road signs. This, in turn, reduces the time available to react to that information and to possibly avoid a crash.

Schieber's ${ }^{25}$ review of current literature also found that shrinkage in the field of vision leads to increasing crash risk. A reduced useful field of view means that some hazards and changes in the environment out of the direct line of sight are recognized later by older drivers. Once again this reduces the time available to react and to possibly avoid a crash.

\section{Cognitive skills}

Cognition refers to thought processes and factors relating to these processes. Many cognitive skills are used in driving, including memory, processing of sensory information, and mental agility. A decline in cognitive ability has been linked with increased crash risk in the elderly.

Memory, both short- and long term, is the mental process whereby people store knowledge and experience. Research shows older adults are less able to handle higher levels of complexity and suggests they generally experience some reduction in shortterm memory capacity. Age impacts long term memory differently. The primary agerelated differences in long-term memory are in the ability to commit new information to long-term memory and some differences in the rate of accuracy in the information retrieved. ${ }^{26}$ Lundberg et al. ${ }^{27}$ suggest that the link between safe driving and memory may be a correlated and not a causal relationship. A decline in memory skills often signals the onset of dementia which increases crash risk. The crash involvement rate of seniors suffering from Alzheimer's disease is at least twice as high as the crash history of seniors without cognitive impairments.

Other cognitive skills that decline with age and are important to driving proficiently are the ability to switch from one behavioural activity to another (cognitive flexibility), the ability to switch from automatic to controlled responses (mental flexibility), and the ability to monitor several stimuli simultaneously (divided attention). De Raedt and

\footnotetext{
${ }^{24}$ Eby et al. (1998).

25 Schieber (1994).

${ }^{26}$ Eby et al. (1998).

${ }^{27}$ Lundberg et al. (1998).
} 
Ponjaert-Kristoffersen ${ }^{28}$ find that cognitive flexibility is positively correlated with driving safely. Many driving situations require divided attention - monitoring driving speed and watching traffic flow - and Salthouse et $a l^{29}$ note the elderly have a significantly decreased ability to divide attention compared to younger adults.

\section{Motor function}

Several types of motor functions, such as muscle strength, flexibility, and endurance affect driving skill. Eby et al. ${ }^{30}$ again provide a good summary of the medical findings on the issue of flexibility. They report research findings that older adults with less joint flexibility exhibited poorer on-road driving ability and that discomfort while seated can lead to early and excessive fatigue and distraction. Restrictions in range of neck motion can impede the older driver's ability to scan to the rear, back up, and turn the head to observe blind spots.

\section{Medications}

The issue of drug use in older Canadians is one of legal use of prescription and overthe-counter drugs. Sanmartin et al. ${ }^{31}$ estimate that 88 per cent of Canadians over the age of 65 years used prescription medication in the past month and many seniors have chronic illnesses for which they take several products. Some of these medications adversely impact driving ability: Zhang et al $^{32}$ find the incidence of prescription drug usage among at-fault elderly drivers in fatal crashes was double that of young (age 16-24 years) at-fault drivers and more than 50 per cent greater than that of middleaged (age 25-64 years) at-fault drivers.

\section{Actuarial issues: age as a risk classification variable}

Having reviewed the existing trends and literature on the abilities of young and old drivers, we now turn our attention to how insurers use risk characteristics, such as age, to price insurance. We review criteria by which to evaluate classification variables and provide a discussion on the use of age as a classification variable for individual life, health and automobile insurance. Continuing with our focus on automobile insurance, we provide a brief summary of the use of age in pricing and delivery of automobile insurance in Canada and internationally.

\section{Defining efficient underwriting variables}

The theory of insurance pricing begins with a straightforward analysis of the economics of information which quickly reveals the potential benefits available to

\footnotetext{
${ }^{28}$ De Raedt and Ponjaert-Kristoffersen (2001).

${ }^{29}$ Salthouse et al. (1989).

${ }^{30}$ Eby et al. (1998).

${ }^{31}$ Sanmartin et al. (2004).

${ }^{32}$ Zhang et al. (1998).
} 
sellers who separate consumers by risk type. An insurer that fails to base premiums on information known to be correlated with differences in expected claims will lose money to adverse selection. This generally explains why classification variables are used in a competitive marketplace when the cost of implementing them produces a net gain. In this section, we evaluate the usefulness of age as a classification variable for life, individual health, and automobile insurance according to actuarial, operational, social, and legal criteria as described by Finger. ${ }^{33}$

The analysis of age as a classification variable is summarized in Table 2, which reviews how well age meets the classification variable criteria for the personal coverages of auto, life and health insurance. Although the focus of this article is auto insurance, examination of other personal lines provides insight into the reasons why age often is challenged as a classification variable for automobile insurance, but almost never questioned when it is applied to life and health insurance.

\section{Actuarial criteria}

Following Finger, ${ }^{34}$ a classification variable is deemed to be actuarially fair if it is accurate, provides for homogeneity across members, displays statistical credibility, and is reliable over time. To prevent adverse selection, the single most important criterion is accuracy: an accurate classification variable partitions insureds so each pays a premium proportional to his/her expected claims cost or underwriting expenses. Homogeneity requires that all insureds within the same risk class should have the same expected claims costs. A large number of insureds are needed in each group for the past claims history of the group to be statistically credible. Too few members result in losses that vary greatly between years and cause premiums to fluctuate similarly. And finally a reliable classification variable produces cost differences between different groups that remain relatively stable over time.

For all personal lines of insurance, age has shown to be both an accurate and reliable classification variable. At the youngest ages, sufficient experience is available to credibly rate both life and automobile insurance, though that statement is less true for individual health insurance. At the oldest ages, enough experience is available to credibly rate both life and individual health insurance, but not auto insurance. For both young and old drivers, their greater heterogeneity of skills and ability leads to greater intraclass differences in risk exposures for driving than is observed in other age classes. After accounting for environmental factors, the same level of heterogeneity is not present in either life or individual health insurance. In general, however, age has been shown to be an actuarially fair classification variable for all three lines of personal insurance considered.

\section{Operational criteria}

Some actuarially fair risk classification variables cannot be practically implemented because they do not possess the operational criteria of objectivity, low cost

\footnotetext{
${ }^{33}$ Finger (1996)

34 Ibid.
} 
Table 2 Age as a classification variable: criteria satisfied

Legal criteria

Allowable under Regulations

Strong relationship between age and expected claims

For some age groupings, there is a high degree of homogeneity, but not for others.

Credibility of experience

Except at perhaps very old ages, sufficient experience for credible ratings Yes, strong relationship over time

Yes

Yes

Yes, age used for several purposes Not in general, especially for young drivers

Depends on age groupings.

Big decrease in insurance prices for

$<25$ and $>25$ age groups

No real privacy concerns, most people don't mind revealing their age

No. Age does not make one a poor driver; rather conditions associated with age affect driving ability

Controllability No

Affordability and Availability Concern for both young and old drivers
Life insurance

Individual health insurance

Strong relationship between age and expected claims

Yes, in general, after accounting for environmental factor

Yes, sufficient population at every age group

Yes, strong relationship over time

Yes

Yes

Yes, age used for several purposes

Yes, strong medical evidence

Yes, at least between consecutive age groups

No real privacy concerns, most people do not mind revealing their age

Yes

No

Yes, elderly most likely cannot afford life insurance, but unlikely to need it
Strong relationship between age and expected claims

For some age groupings, there is a high degree of homogeneity, but not for other

Yes, sufficient population at every age group

Yes, strong relationship over time

Yes

Yes

Yes, age used for several purposes

Yes, strong medical evidence

Yes, at least between consecutive age groups, although there are considerable increases for older ages.

No real privacy concerns, most people do not mind revealing their age

Yes, though perhaps weaker for chronological age than physical age

No

Yes, elderly most likely to need health insurance but likely cannot afford it 
implementation, and difficulty to manipulate. The cost of classifying individuals according to a specific variable must be much less than the cost differentials produced by using that variable in the classification scheme. Data that are cumbersome and expensive to collect and verify seldom make good classification variables. Related to the objective of low administrative costs, data used for another purpose make good risk classification variables. Using a variable that is reported or collected by other agencies reduces the likelihood of it being manipulated and decreases the cost of verification.

A classification variable must provide little ambiguity across insureds, and the total classes described by the variable must be mutually exclusive and exhaustive. For a classification variable to be objective, it must result in two different underwriters classifying a risk in the same manner. A related criterion is that a variable should minimize discontinuities between classes since this reduces the incentive for insureds to manipulate the classification variable. Sometimes this is achieved by having several levels of a classification variable, which minimizes the resulting rate differential between any two adjacent groups. And finally, insureds and regulators are happiest if the risk classification variable shows an intuitive relationship between the variable and expected costs.

Age is an excellent variable from an operational perspective. It is objective, its collection attracts low administrative cost, and it is not easy to manipulate as it can be easily confirmed from birth certificates and other forms of government identification. Most insureds recognize an intuitive relationship between age and claims costs for life and health insurance. Despite the mounting evidence produced from medical research summarized in the first section, the relationship between age and driving ability is less well understood and less widely accepted among the general population.

The final operational criterion is that the classification variable should minimize discontinuities between age groups. This is true, at least between consecutive age groups for both life insurance and for individual health insurance. This criterion does not hold for automobile insurance. A large difference often is observed between the premiums charged to drivers under the age of 25 years, and for those over 25 years. We have not yet seen a large increase in premiums for those over the age of 65 years, although we have seen the elimination of discounts that many insurers previously offered to seniors.

\section{Social criteria}

A third consideration in the selection of risk classification variables is social acceptability. The four main criteria here are privacy, causality, controllability and affordability/availability. Privacy affects individuals' willingness to disclose some information which, in turn, affects the accuracy of a risk classification variable as well as the ease with which it can be collected and verified. Causality requires more than an intuitive relationship between the classification variable and the expected losses. A good risk classification variable should encourage individuals to act to reduce the expected frequency and/or severity of their losses - the criterion of "controllability". The social criterion of affordability/availability requires that those who need to purchase insurance protection can reasonably do so. 
With age, no real privacy concerns arise as most people do not mind revealing this for classification purposes. Obviously though, this variable is beyond the control of the insured. There is a strong causal relationship between age and life insurance, and to a lesser extent between age and individual health insurance, although once again a distinction can be made between chronological and functional/physical age. The link between age and driving ability is less direct. Age is associated with conditions, such as immaturity in young drivers and restricted mobility in older drivers, which tend to affect driving ability. However, the heterogeneity in driving abilities for both these age groups weakens causality arguments.

Using age as a classification variable raises concerns of affordability and availability for both life and medical coverage for the elderly. However, most elderly do not need large amounts of life insurance, so the issue is not a high social priority. The elderly, however, are the ones most likely to need health care. Because of a greater dependence on private health insurance in the U.S., affordability and availability concerns with respect to that coverage for seniors has been a much larger policy issue there than in Canada. The existence of residual pools for automobile insurance in Canada prevents the use of age from impeding the availability of auto insurance. However, severe affordability issues are associated with young and, more recently, with elderly drivers. This is driven by the combination of high costs of automobile insurance and the restricted incomes of many young and elderly people.

\section{Legal criteria}

In practice, the use or prohibition of certain classification variables most often is imposed by statute and/or implementing regulation. ${ }^{35}$ In Canada the provincial statutes, which are typically more restrictive, require generally that classification variables not be unfairly discriminatory, that is, that the actuarial criterion of accuracy must be shown. However, classification variables have sometimes been prohibited because there exists only a correlated and not a causal relationship between the classification variable and the expected loss costs or because they have been deemed to be socially unacceptable. The legal criteria, obviously, vary not only by state and province, but vary by nation as well.

To our knowledge, no restrictions exist anywhere on the use of age as a classification variable for life insurance. However, some jurisdictions have restricted the use of age as a classification variable for both individual health and automobile insurance. We discuss these restrictions in more detail below.

${ }^{35}$ Although this section refers exclusively to statutory requirements, we recognize that legal precedent is developing globally to define criteria for justification of unequal treatment, generally including (1) controllability, (2) causality, (3) skepticism on adverse selection, (4) whether the classification is welfareimproving, and (5) the cost of information tracing. As summarized in Thiery and Van Schoubroeck (2005, p. 18), the justification test to deal with the alleged discriminatory character of unequal treatment has been developed in a rich array of case law from the European Court of Justice (e.g.,ECJ 13 May 1986, case 170/84, Bilka, ECR 1986, 1607; ECJ 1 July 1986, case 237/85, Rummler, ECR 1986, 2101; Teulings; ECJ 31 March 1981, case 96/80, Jenkins, ECR 1981, 911; ECJ 27 October 1993, case C-127/92, Enderby, ECR 1993, I-5535), the European Court of Human Rights e.g. ECHR 28 May 1985, Abdulaziz, Series A, vol., and national constitutional courts. 
We review, in this section, the use of age as a classification variable both in Canada and internationally. We summarize restrictions on age as a classification variable for automobile insurance, as well as the impact of age on the issuance of auto insurance policies, in jurisdictions worldwide.

In private Canadian marketplaces, a set of legal precedents has resulted in auto insurers being allowed to price discriminate on the basis of age. The landmark case on this point is Zurich Insurance Co. v. Ontario. ${ }^{36}$ In that ruling, the Supreme Court of Canada found the statistical evidence showing young male drivers to be involved in proportionately more serious accidents than other drivers makes charging these drivers higher premiums a sound and accepted insurance practice. The Supreme Court ruled that the insurance industry could continue to use discriminatory criteria such as age and marital status as a bona fide means of assessing risk, but that the industry could not do so indefinitely. The Courts encouraged insurers to find a new classification system that does not use age, gender and marital status, or at the very least to explore whether such non-discriminatory classification variables exist.

Although to date no alternative classification variables have been found, some provinces have recently amended their respective Insurance Acts to restrict the use of age as a classification variable. In Nova Scotia, insurers are prohibited from using a risk classification variable that is deemed to be subjective, arbitrary, contrary to public policy and which bears little or no relationship to the potential risk assumed by the insurer. For automobile insurance, the Act lists several prohibited risk classification variables, including age and marital status of the insured. ${ }^{37}$ Other provinces in Atlantic Canada have enacted similar restrictions. In addition, the government-run automobile insurance schemes in British Columbia, Saskatchewan, Manitoba, and Quebec do not classify drivers by age, gender, or marital status.

Elsewhere the use of age to rate automobile insurance remains a contentious issue. The Ontario Human Rights Commission, while accepting the correlation between age and accident history, "submits that causal relationships would be preferable because they are a more bona fide and reasonable business practice". ${ }^{38}$ A study done by the Insurance Bureau of Canada ${ }^{39}$ in Alberta showed that overall 55 per cent of Albertans believe age should continue to be a factor in determining insurance premiums, with less support from younger drivers and more from older drivers.

The U.S. experience with age and automobile insurance largely mirrors that in Canada. Some jurisdictions allow insurers to underwrite on the basis of age and gender; some do not. For example, New York allows automobile insurers to price insurance based on age and gender, but the insurance law "forbids an insurance company from refusing to issue a policy or terminating a policy because of the race, creed, color, national origin, disability, sex, marital status or advanced age of an

\footnotetext{
${ }^{36}$ Zurich Insurance Co. v. Ontario (Human Rights Comm.) (1992), SCR 321.

${ }^{37}$ Nova Scotia (2003).

${ }^{38}$ http://www.ohrc.on.ca/en_text/consultations/insurance-consultation-report_3.shtml

${ }^{39}$ Insurance Bureau of Canada (2005).
} 
insured or applicant". ${ }^{40}$ Michigan does not allow automobile insurers to rate on age or gender.

In the United Kingdom, age discrimination concerns regarding auto insurance appear to centre on the issuance of policies. In Ross versus Royal SunAlliance, ${ }^{41}$ the insurer was found to be discriminating by refusing to issue a quote to Mr. Ross because he was over 70 years old. The Equity board ruled that although insurers may charge actuarially supported discriminatory rates under the Equity Status Act of 2000, companies cannot refuse to provide a quote based solely on an individual's age.

\section{Alternative underwriting variables for automobile insurance}

This section focuses on risk classification for auto insurance and the charge in the Zurich decision that insurers explore whether non-discriminatory classification variables could be used to classify drivers. This section evaluates a range of risk classification variables proposed for use either in place of or in conjunction with age (and gender). The variables examined are number of years licensed, driving record, safe driving rewards for young drivers, distance travelled, and insurance scores. The performance of these variables and any disproportionate impact on young and elderly drivers are discussed.

Michael Miller, ${ }^{42}$ in previously unpublished work, examined the importance of age as a rating variable for automobile insurance in the United States in explaining accident history. Using 2.7 million U.S. auto insurance claims, Miller looked at the explanatory power of classification variables with respect to accident risk. His results, presented in Table 3, find age and gender (used in combination) to be the single most powerful characteristic in explaining losses in liability lines of automobile insurance. Age and gender consistently rank higher than driving record, and in most cases explain more interinsured variation than insurance score. These results provide strong statistical evidence that other variables are unlikely to capture the heterogeneity in driving risk arising from age.

\section{Number of years licensed}

The use of years licensed as a rating variable is used both in jurisdictions that allow age as a classification variable and in jurisdictions which prohibit age as a classification variable. When used in conjunction with age, one might expect that years licensed should be negatively correlated with driving risk. Specifically, years licensed captures the learning argument - new drivers pose a greater risk than experienced drivers because of the complexity of driving.

In jurisdictions that prohibit age as a rating variable, the use of years licensed becomes a statistical proxy for age because a large proportion of all drivers get their license to drive in their teens or early twenties. However, evidence from government-

\footnotetext{
${ }^{40}$ http://www.ins.state.ny.us/auto0406.htm

${ }^{41}$ Equity Officer Decision DEC-S2003-116. File number ES/2001/164.

${ }^{42}$ Miller (2004).
} 
Mary Kelly and Norma Nielson

Table 3 Ranking of underwriting variables by importance in explaining inter-insured variation

\begin{tabular}{cllllll}
\hline Factor & BI liability & PD liability & Personal Injury & Med pay & Comprehensive & Collision \\
\hline 1 & Age/gender & Age/gender & Ins. score & Ins. score & Model year & Model year \\
2 & Ins. score & Ins. score & Territory & Limit & Age/gender & Age/gender \\
3 & Territory & Territory & Tenure & Age/gender & Ins. score & Ins. score \\
4 & Model year & Model year & Age/gender & Mileage & Territory & Tenure \\
5 & Accidents & Accidents & Model Year & Accidents & Deductible & Accidents \\
6 & Mileage & Violations & Multi-line & Multi-car & Violations & Territory \\
7 & Violations & Mileage & Violations & Territory & Mileage & Deductible \\
8 & Tenure & Tenure & Mileage & Tenure & Tenure & Violations \\
9 & Limit & Multi-Line & Accidents & Multi-line & Multi-car & Multi-line \\
10 & Multi-Line & Multi-Car & Multi-car & Violations & Multi-line & Mileage \\
\hline
\end{tabular}

Source: Miller, Michael J. "Alternatives to age and gender as rating variables" presented at Auto Insurance "Think Tank” (Calgary, AB), March 2004.

run automobile insurance systems in British Columbia, Saskatchewan, Manitoba, and Quebec suggests that years licensed as a classification variable (without also considering age) is less powerful. Those provinces, which rate according to number of years licensed but do not classify drivers by age, gender, or marital status, have a higher motor vehicle injury per million passenger kilometers than the provinces where risk-based (i.e. rating by age and gender of the insured) premiums are used. ${ }^{43}$ Another study found automobile fatality rates were 18 per cent higher and hospital admissions from auto accidents for males aged 16-24 years were 59 per cent higher in 2000 in these provinces than for private auto insurance markets. ${ }^{44}$ Both of these statistics suggest more extensive moral hazard when age is eliminated from the classification system.

In the absence of an age variable, we would expect a U-shaped actuarial relationship between years licensed and risk, that is, a similar one to the relationship between age and driving risk. To date, in Canada, this U-shaped curve for years licensed as a classification criterion is reflected in practice by charging more for new drivers and drivers that have had their license for fifty or more years. While that implementation has not been challenged as discriminatory, the strong positive correlation between these two variables could easily lead to challenges by a Human Rights Commission in a jurisdiction that outlaws the use of age as a rating variable.

Because insurers in Canada have been able to use years licensed in this manner when age has been removed from the risk classification process, little research has been done on the effects anticipated if that variable too were to be eliminated from the set considered socially acceptable.

From a practical standpoint, using number of years licensed instead of age as a rate classification variable groups young new drivers with older, but inexperienced drivers. In that environment, young drivers would pay a lower premium and older but

\footnotetext{
43 The Insurance Bureau of Canada (2005).

${ }^{44}$ Leadbetter and Kovacs (2003).
} 
inexperienced drivers would pay a higher premium. However, because this rate class would be dominated by young drivers, the rate increase for older drivers would be significantly greater per capita than rate reductions for young drivers.

At the other end of the spectrum, elderly drivers who learned to drive later than the norm would pay a lower premium than elderly drivers who have been driving since their teen years. In essence, this would create a system where "newer" drivers who are facing age-related functional decline in abilities without as much driving experience to compensate would be paying the lowest rate of all in their age cohort.

\section{Driving record}

Driving records reflect choices made by an individual in the precise setting relevant to the insurance transaction; as such it is an intuitive variable to use in underwriting the risk of a driver. The number of moving violations and accidents incurred by either the insured or the vehicle is used in all jurisdictions today, sometimes together with age and sometimes in place of age. In most North American jurisdictions, insurers offer discounts for the number of consecutive years of claims-free driving, and may have surcharges for moving violations and at-fault accidents. In Europe and Asia, this system is often referred to as a bonus-malus system. The benefits of such a system are twofold. It reduces moral hazard by transferring some of the cost of the loss (or expected cost arising from dangerous driving) back to the insured via future premiums. In addition, the use of a bonus-malus system allows insurers to capture ex post additional risk information that was not captured by the ex ante rating variables used.

Generally, the statistical predictability of driving records is valid if the past is a good predictor of the future. A bonus-malus system is ideal for classifying risks over time, given that an individual's risk propensity is not changing. It is also an important tool for reducing moral hazard. For new drivers, however, it is important to understand that the absence of any record at all is not the same as an experienced driver having successfully driven for a specified period without an accident or moving violation. With the new licensee, the lack of violations simply means no information is available and so the driving record cannot be used to categorize new drivers. For this population there is no past information from which to predict the future.

The issue becomes quite different at the older end of the age spectrum. As functional ageing occurs the past information becomes less reliable as a predictor of the future; driving record begins to lose its predictive power as a classification variable. An atfault accident becomes a more serious signal for an elderly driver than from a middleage driver. In practice, middle-age drivers may receive a slight premium penalty following an at-fault accident while an elderly driver often has his or her insurance cancelled. When that happens the insurer is essentially viewing an elderly driver's atfault accident as a sign of reduced fitness to drive. If indeed an elderly driver's at-fault accident is a signal of a reduced fitness to drive, then simply imposing additional costs based on a deteriorating driving record (imposing the malus penalty) will not produce the needed result if indeed a material decline in driving ability has occurred. Few would argue that it is equitable to allow bad drivers to remain on the road so long as 
they have not exceeded their ability to pay rising insurance premia while restricting the mobility of bad drivers with fewer financial resources.

In practice, the expected result of eliminating age as a classification variable and using only a driver's record is higher premiums for drivers between the ages of 25 and 65 years and much lower premiums for young and old drivers. We conjecture that the imposition of such constraints on classification would lead insurers to see greater heterogeneity within all rate classes, and more homogeneity between rate classes.

\section{Young driver maturity}

Some insurers have attempted to partition the heterogeneous group of young drivers by creating a measure of driver maturity or responsibility. A good student discount for those who have a grade point average above a specified threshold has been used by insurers in both Canada and the U.S. as a surrogate for responsibility. Good grades may reflect both choices made by a student and that student's level of responsibility. One can argue that there exists a correlated and not a causal relationship between good grades and safe driving, but according to insurers that use this classification variable, it satisfies the actuarial criteria set forward in the section on the actuarial criteria.

Similar to the use of driving record, one Canadian insurer has introduced a programme to reward young drivers for claims-free driving. Young drivers are eligible to receive their 4th year of coverage free if they complete 3 consecutive years with no at-fault accidents and no driving convictions. ${ }^{45}$ This classification approach attempts to partition the heterogeneous class of young drivers, ex post. Such a programme also promotes loss control among young drivers, providing them with a strong incentive to drive safely. This is particularly important as research has shown that crash rates drop dramatically during the first 2 years of driving experience. ${ }^{46}$

\section{Distance driven}

The typical measure of exposure for auto insurance is "one car year". That is, insurance covers the named vehicle for a specific length of time. Litman ${ }^{47}$ and others argue that society would benefit from shifting automobile insurance from a fixed cost into a variable cost for a vehicle based upon its usage. Proponents of the so-called distance-based pricing argue that measuring exposure in terms of distance is more equitable and economically more efficient. Such pricing is seen as valid by many consumers because of the overall direct causal relationship between decisions to drive and expected accidents. ${ }^{48}$ Young and elderly, however, drive less and have significantly higher crash rates per kilometer driven than drivers aged 25-65 years. If distance-based pricing were used in conjunction with age as a rating variable, these

\footnotetext{
45 www.cooperators.ca/english/products/auto/safe_driving_reward.html

46 Mayhew et al. (2003).

${ }^{47}$ Litman (1999).

${ }^{48}$ While this relationship can be validated for the overall population, the data do not support a conclusion that the rate (per distance driven) should be the same for drivers of all ages.
} 
drivers will pay a much higher rate per distance driven than drivers between the ages of 25-65 years. To summarize, changing the exposure unit does not address the underlying higher crash risk of these drivers, but it could provide an important incentive to drive less and, in that way, could reduce accident rates.

Insurers' greatest concerns with distance-based pricing are not related to the accuracy or fairness of the results but rather to operational and social factors. If insurers rely on a self-reporting mechanism to track distance, that variable becomes subject to moral hazard; alternatively, if distance is tracked using GPS technology, then privacy concerns immediately emerge. A secondary problem has been the slowness of regulators in many jurisdictions to clearly indicate their willingness to accept a distance-based exposure unit. $^{49}$ Because of cost, operational concerns, regulatory uncertainties, and a lack of actuarial data regarding distance as an indicator of risk, insurers in Canada have not embraced a distance-based exposure unit. That time may be receding rapidly, however. Aviva Canada ${ }^{50}$ has announced a trial programme offering premium discounts of 5 to 25 per cent for customers who agree to use technology to track how much, how fast, and the time of day a vehicle is driven.

\section{Insurance scores}

A relatively recent innovation to measure an individual's risk propensity is an insurance score that incorporates elements of one's credit and insurance purchasing history. The score, which measures how an individual manages his or her financial affairs, does not include personal information such as race, gender, age, marital status, or income. The best information on the reliability of insurance scores comes from the U.S. where more than 90 per cent of U.S. personal lines insurers in 2001 used credit information to produce insurance scores. The insurance score, typically a number between 200 and 1,000 has proven to be highly correlated with losses.

The insurance score shows much promise in capturing the heterogeneity of drivers, but also is quite controversial. Insurance scores, and possible racial or socioeconomic status discrimination arising from their use, have been examined in several jurisdictions in the United States. The Texas Department of Insurance ${ }^{51}$ supported the use of insurance scores stating they were not unfairly discriminatory, and did not have a disproportionate impact across different racial groups.

A study of insurance scores from the Office of Insurance Commissioner in Washington State ${ }^{52}$ examined that state's data for possible discrimination. It concluded that ethnicity was significant in some situations (Asian Americans were found to have the best insurance scores) and that income was also significant. One

\footnotetext{
${ }^{49}$ One exception is the state of Texas where insurers are allowed to file premium plans based on the traditional statistical exposure of time and a distance-based exposure unit. In the United Kingdom, Norwich Union has offered a limited subscription pay-as-you-drive programme for young drivers in 2005. In addition, Norwich Union is charging differential premiums based on the time of day the vehicle is used - charging young drivers more for driving after 2300.

${ }^{50}$ Aviva Canada (2005).

${ }^{51}$ Texas Department of Insurance (2005).

52 Pavelchek and Brown (2003).
} 
strong conclusion from this study was that the elderly had the best insurance scores and would benefit most from insurance scoring. Gender and marital status were found to be less important.

From the available evidence, it appears that using insurance scores in automobile insurance might allow insurers to rely less heavily on age as a proxy for driver risk. However, Human Rights commissions in Canada have raised concerns that the insurance score itself might be discriminatory. Furthermore, any new classification variable introduced is likely to be required to meet a higher standard than existing risk classification variables. For example, the Ontario Human Rights Commission states:

Any newly proposed risk classification system, even if shown to be a better measure of risk, should at least not further contravene rights under Part 1 of the Code any more than any current classification system does. ${ }^{53}$

The Commission further asserted that some factors included in an insurance score might contravene Part I of the Code on the grounds of marital status and that even in the absence of conclusive evidence of discrimination, this variable might adversely impact women, youth, and recent immigrants. Because much of the U.S.-based research on insurance scores has centred on issues of possible racial discrimination, the available research is far less solid on possible age, gender, and marital status discrimination.

A practical concern for insurers is that young drivers likely have inadequate credit history to permit computation of insurance scores. Similar concerns arise concerning the reliability of insurance scores for the elderly. Hartwig and Wilkinson ${ }^{54}$ note that only 4 per cent of consumers in the U.S. have no credit history. They speculate that these might be the very young, the very old, and those that do not use credit for personal or religious reasons. Furthermore, if poor driving experience among the elderly arises because of functional and cognitive disabilities and not the risk-taking behaviour captured by the insurance risk score, then the power of insurance scores to accurately classify elderly drivers is immediately lessened.

In summary, insurance scores face two large hurdles before they can supplant age in the rating and underwriting processes of insurance in Canada. The first concerns whether this variable contravenes provincial Human Rights Codes. The second is that the age groups of greatest concern are precisely the groups least likely to generate reliable insurance scores. Additional research into validity of insurance risk scores is needed across different age groups before either of these concerns can be addressed conclusively for the Canadian population.

\section{Conclusion}

Because of the social undesirability of discriminating by age, governments and insurers alike have looked carefully at the possibility of eliminating age as a classification

\footnotetext{
${ }^{53}$ Ontario, Human Rights Commission (1999, p. 27).

${ }^{54}$ Hartwig and Wilkinson (2003).
} 
variable for personal insurance. From our review of age and discrimination in insurance, few if any concerns about age discrimination have emerged regarding life and health insurance. The emphasis is on automobile insurance where Canada faces important, but significantly different, policy problems with regard to young and old drivers. Insurers find that the mere presence of a driving license is not an accurate assessment of the risk posed by young and elderly drivers. Too much heterogeneity in driving ability remains within these two age groups - much more than is found within any other age group. Insurers require a risk classification variable that captures this heterogeneity. At the present time in the private marketplace, the inclusion of age in the design and distribution of auto insurance captures real differences among prospective insureds thereby ensuring that each purchaser of insurance pays a premium that more accurately reflects the expected losses of that individual than would be possible without considering age. Among the alternatives examined, we find that the insurance risk scores best captured driver risk. This variable, however, may not be actuarially sound for very young and very old drivers and may itself contravene provincial Human Rights Codes.

A separate consideration is whether insurers can rely less heavily on age as a classification variable. A review of the literature finds that the best solutions to reducing the importance of age in auto insurance remain outside the realm of insurance. For young drivers the literature suggests that the two-pronged approach of improving new driver education and bestowing full driving privileges in a more gradual fashion are achieving many worthwhile objectives. Continued research into the results achieved in these two areas (separately and collectively) should allow development of a "best practices" model for new drivers.

Unlike youthful drivers, the elderly often see changes that are permanent and that tend to result in poorer driving ability. Ultimately testing for a driver's license should signal a minimum fitness to drive. The reliance on age as an underwriting variable can be decreased through better assessments of fitness to drive and through the implementation of changes that increase road safety for all road users. To the extent that the implemented changes are successful, insurance rates for the elderly will remain stable and affordable.

Overall, research shows that the age variable is capturing real differences among insureds (and prospective insureds) that are not captured by any of the other variables examined. Age is not arbitrary and it is not redundant. Therefore, we have not reached the point where age can be eliminated from insurance processes without creating market disruptions and increases in moral hazard that are themselves undesirable.

\section{References}

Aviva Canada (2005) 'Aviva Canada Autograph ${ }^{\mathrm{TM}}$ Program Offers Ontario Drivers More Choice and Control over their Auto Insurance', Scarborough, ON: Aviva News Release, online: https:// www.avivacanada.com $/$ minimal.php? content $=$ MEDIA_RELEASE\&language $=$ ENGLISH\&name $=$ 2005-03-07.

Beirness, D.J., Mayhew, D.R., Simpson, H.M. and Desmond, K. (2004a) The Road Safety Monitor 2004: Young Drivers, Ottawa, ON: Traffic Injury Research Foundation.

Beirness, D.J., Simpson, H.M., Desmond, K. and Mayhew, D.R. (2004b) The Road Safety Monitor 2004: Drinking and Driving, Ottawa, ON: Traffic Injury Research Foundation. 
Bess, I. (1999) 'Seniors behind the wheel', Canadian Social Trends 54: 2-7.

Clarke, D.D., Ward, P. and Truman, W. (2005) 'Voluntary risk taking and skill deficits in young driver accidents in the UK', Accident Analysis and Prevention 37: 523-529.

De Raedt, R. and Ponjaert-Kristoffersen, I. (2001) 'Predicting at-fault car accidents of older drivers', Accident Analysis \& Prevention 33: 809-819.

Eby, D.W., Trombley, D.A., Molnar, L.J. and Shope, J.T. (1998) The Assessment of Older Drivers' Capabilities: A Review of the Literature, Report UMTRI 98-24, The University of Michigan Transportation Research Institute, Ann Arbor, MI.

Finger, R.J. (1996) 'Risk classification', in Casualty Actuarial Society (ed) Foundations of Casualty Actuarial Science, Baltimore, MD: United Book Press, pp. 233-282.

Hartwig, R.P. and Wilkinson, C. (2003) 'The use of credit information in personal lines insurance underwriting', Insurance Issues Series 1: 1-20.

Health Canada (1999) Statistical Report on the Health of Canadians, Ottawa, ON: Health Canada.

Insurance Bureau of Canada (2005) Auto Insurance and Young Drivers - The Facts, from http://www.ibc.ca/ home_alta_youngdrivers.asp, accessed on 12 February 2005.

Law Commission of Canada (2004) Does Age Matter? Law and Relationships between Generations, from http://www.lcc.gc.ca,accessed 1 December 2004.

Leadbetter, D. and Kovacs, P. (2003) The Influence of the Social Pricing of Insurance on Road Safety in British Columbia, Insurance Bureau of Canada Report, from http://www.urban-renaissance.org/ urbanren/publications/socialpricing.pdf,accessed on 15 April 2005.

Litman, T. (1999) 'Distance-Based Charges: A Practical Strategy for More Optimal Vehicle Pricing, presented at Transportation Research Board 78th Annual Meeting, online at www.utpi.org.

Lundberg, C., Hakamies-Blomqvist, L, Almkvist, O. and Johansson, K. (1998) 'Impairments of some cognitive functions are common in crash-involved older drivers', Accident Analysis and Prevention 30: 371-377.

Mayhew, D.R., Simpson, H.M. and Pak, A. (2003) 'Changes in collision rates among novice drivers during the first months of driving', Accident Analysis and Prevention 34: 683-691.

McKnight, A.J. and McKnight, A.S. (1999) 'Multivariate analysis of age-related driver ability and performance deficits', Accident Analysis and Prevention 31: 445-454.

McKnight, A.J. and McKnight, A.S. (2003) 'Young novice drivers: careless or clueless?' Accident Analysis and Prevention 35: 921-925.

Miller, M.J. (2004) Alternatives to Age and Gender as Rating Variables, presented at Risk Studies Centre Auto Insurance 'Think Tank', Calgary, AB (March).

Mitchell, C. (1997) 'The potential of intelligent transportations systems to increase accessibility to transport for elderly and disabled people', Transport Canada TP 12926E, from http://www.tc.gc.ca/tdc/summary/ 12900/12926e.htm, accessed 15 August 2003.

Nicoletta, J. (2002) Driving Characteristics of the Young and Aging Population, Ottawa, ON: Statistics Canada.

Nova Scotia (2003) Insurance Act, S.N.S. 2003, c. 11, as amended by Automobile Insurance Reform Act, S.N.S. 2003, c. 1.

Ontario Human Rights Commission (2002) Policy on Discrimination against Older Persons Because of Age, from http://www.ohrc.on.ca/english/publications/age-policy.pdf,accessed 18 January 2005.

Ontario, Human Rights Commission (1999) Human Rights Issues in Insurance: A Discussion Paper, from http://www.ohrc.on.ca/english/consultations/insurance-discussion-paper.pdf, accessed 18 January 2005.

Pavelchek, D. and Brown, B. (2003) Effect of Credit Scoring on Auto Insurance Underwriting and Pricing, from http:/www.insurance.wa.gov/publications/news/Final_SESRC_Report.pdf,accessed 17 March 2005.

Renge, K. (2000) 'Effect of driving experience on drivers' decoding process of roadway interpersonal communication', Ergonomics 43: 27-39.

Salthouse, T.A., Mitchell, D.R.D., Skovronek, E. and Babcock, R.L. (1989) 'Effects of adult age and working memory on reasoning and spatial ability', Journal of Experimental Psychology: Learning, Memory and Cognition 15: 507-516.

Sanmartin, C., Ng, E., Blackwell, D., Gentleman, J., Martinez, M. and Simile, C. (2004) Joint Canada/ United States Survey of Health, 2002-03, Statistics Canada Catalogue no. 82M0022XIE, from 
http://www.statcan.ca/english/freepub/82M0022XIE/2003001/pdf/82M0022XIE2003001.pdf,accessed 15 April 2005.

Schieber, F. (1994) Recent Developments in Vision, Aging and Driving: 1988-1994, Report UMTRI 94-26, The University of Michigan Transportation Research Institute, Ann Arbor, MI.

Shinar, D., Meir, M. and Ben-Shoham, I. (1998) 'How automatic is manual gear shifting?' Human Factors 40: $647-654$.

Texas Department of Insurance (2005) Use of Credit Information by Insurers in Texas, from http:// www.tdi.state.tx.us/general/pdf/credit05sup.pdf,accessed 8 February 2005.

Thiery, Y. and Van Schoubroeck, C. (2005) Risk Classification and Public Policy, Presented at the European Law and Economics Seminar, Berlin (June).

Underwood, G., Crundall, D. and Chapman, P. (2002) 'Selective searching while driving: the role of experience in hazard detection and general surveillance', Ergonomics 45: 1-12.

Zhang, J., Fraser, S., Lindsay, J., Clarke, K. and Mao, Y. (1998) 'Age-specific patterns of factors related to fatal motor vehicle traffic crashes: focus on young and elderly drivers', Public Health 112(5): 289-295.

Zurich Insurance Co. v. Ontario (Human Rights Comm.) (1992) SCR 321.

\section{About the Authors}

Dr. Mary Kelly is Assistant Professor of Finance and Insurance at the School of Business and Economics, Wilfrid Laurier University in Waterloo, Ontario, Canada. She teaches property/liability insurance, finance and risk management. Her main research interests are automobile insurance, Canadian financial services and elderly drivers.

Norma Nielson earned a PhD from the University of Pennsylvania in 1979. She holds the Chair in Insurance and Risk Management in the Haskayne School of Business at the University of Calgary where she also serves as interim director of the University's Risk Studies Centre. 